Article

\title{
Assessing the Temporal Response of Tropical Dry Forests to Meteorological Drought
}

\author{
Lidong Zou ${ }^{1,2}$, Sen Cao ${ }^{1,3}$, Anzhou Zhao ${ }^{2,4}$ and Arturo Sanchez-Azofeifa ${ }^{1, *(1)}$ \\ 1 Department of Earth and Atmospheric Sciences, University of Alberta, Edmonton, AB T6G 2E3, Canada; \\ lidong@ualberta.ca (L.Z.); sencao@szu.edu.cn (S.C.) \\ 2 State Key Laboratory of Resources and Environmental Information Systems, Institute of Geographical \\ Sciences and Natural Resources Research, Chinese Academy of Sciences, Beijing 100101, China; \\ zhaoanzhou@hebeu.edu.cn \\ 3 Key Laboratory for Geo-Environmental Monitoring of Coastal Zone of the Ministry of Natural Resources \& \\ Guangdong Key Laboratory of Urban Informatics \& Shenzhen Key Laboratory of Spatial Smart Sensing and \\ Services \& Research Institute for Smart Cities, Shenzhen University, Shenzhen 518060, China \\ College of Mining and Geomatics, Hebei University of Engineering, Handan 056038, China \\ * Correspondence: gasanche@ualberta.ca
}

Received: 28 May 2020; Accepted: 18 July 2020; Published: 21 July 2020

check for updates

\begin{abstract}
Due to excessive human disturbances, as well as predicted changes in precipitation regimes, tropical dry forests (TDFs) are susceptible to meteorological droughts. Here, we explored the response of TDFs to meteorological drought by conducting temporal correlations between the MODIS-derived normalized difference vegetation index (NDVI) and land surface temperature (LST) to a standardized precipitation index (SPI) between March 2000 and March 2017 at the Santa Rosa National Park Environmental Monitoring Super Site (SRNP-EMSS), Guanacaste, Costa Rica. We conducted this study using monthly and seasonal scales. Our results indicate that the NDVI and LST are largely influenced by seasonality, as well as the magnitude, duration, and timing of precipitation. We find that greenness and evapotranspiration are highly sensitive to precipitation when TDFs suffer from long-term water deficiency, and they tend to be slightly resistant to meteorological drought in the wet season. Greenness is more resistant to short-term rainfall deficiency than evapotranspiration, but greenness is more sensitive to precipitation after a period of rainfall deficiency. Precipitation can still strongly influence evapotranspiration on the canopy surface, but greenness is not controlled by the rainfall, but rather phenological characteristics when leaves begin to senesce.
\end{abstract}

Keywords: meteorological drought; tropical dry forests; NDVI; LST

\section{Introduction}

Tropical dry forests (TDFs) are defined as a vegetation type of which at least $50 \%$ of the trees are drought deciduous, with a dry season of three or more months (precipitation $<100 \mathrm{~mm} / \mathrm{month}$ ), a mean temperature of $25^{\circ} \mathrm{C}$ or higher, and a total annual precipitation of 700-2000 mm [1]. TDFs are considered the first frontier for economic and social development in Latin America and account for roughly $42 \%$ of all tropical forests worldwide [2,3]. They provide diverse ecosystem benefits, such as food, timber, non-timber forest products, biofuels, soil erosion control, soil fertility regulation, water quality improvements, carbon storage, and they help control carbon emissions [4-6]. TDFs have greatly benefitted human development and are considered the most excessively utilized and least protected forest ecosystems of the Americas [1,7-9]. More than $60 \%$ of TDFs have been destroyed in Latin America, and approximately half of all TDFs in the world have been converted to other land use types $[9,10]$. 
As TDFs undergo excessive human disturbances, ongoing climate change is interfering with the provision of ecosystem services [11]. Global climate models have predicted an increase in the frequency, intervals, and severity of meteorological droughts in tropical regions [12]. TDFs are particularly sensitive to meteorological droughts because water dynamics determine the alternating seasonality between wet and dry seasons [13].

Meteorological droughts are recurring climate phenomena that mainly occur when rainfall is significantly less than the normal level for a sustained period [14]. They can also be related to high temperature and high potential evapotranspiration [15]. Meteorological droughts can cause other types of droughts, such as agricultural (lack of soil moisture in the root zone), hydrological (lower than normal stream-flow or reservoir storage), groundwater (reduced groundwater level, recharge or discharge that leads to drying of wells, and failure of capillary rise to vegetation), and economic droughts (shortage of water supply for economic goods) $[14,16,17]$.

To quantify a meteorological drought, including its severity, magnitude, duration, and spatial extent, many drought indices have been developed by integrating ground-station variables, including precipitation, evapotranspiration, and temperature, into one single variable [16]. Popular meteorological indices include the standardized precipitation index (SPI) [18], the standardized precipitation evapotranspiration index (SPEI) [19], and the Palmer drought severity index (PDSI) [20]. The calculation of the PDSI is based on prior precipitation, moisture supply, runoff, and evaporation demand. It was designed for long-time scales (between 9 and 12 months) and is not able to identify droughts of shorter periods. Both the SPI and SPEI are multiscale meteorological drought indices. The SPI is a precipitation-based drought index that considers the essential character of a drought as the deficiency of usable water, including water from soil moisture, rivers, streams, groundwater, and reservoir storages. The SPI is calculated by fitting precipitation totals to a gamma distribution in different time scales and then transforming the gamma distribution to the standard normal distribution. The SPEI is an extension of the SPI, which considers both precipitation and temperature as factors that can trigger drought. The calculation of the SPEI requires multiple data sources as input, including relative humidity, temperature, wind speed, and solar radiation [19]. The high data requirement for the SPEI restricts its wide application, and the SPI is considered the most widely used and valid meteorological drought index [21].

Increases in the frequency, intervals, and severity of meteorological droughts have led to changes in the structure, function, and composition of tropical ecosystems [22,23]. The primary response of forests to drought is to reduce the primary production and water use as a result of reduced soil moisture and stomatal conductance [24]. Secondary effects occur under severe meteorological drought conditions with an extreme decline in productivity. In this case, forest mortality is increased due to carbon starvation and hydraulic failure [25], and susceptibility to insects and disease increases due to physiological changes experienced by host trees [26], and the frequency or intensity of wildfires increases due to a reduction in decomposition processing [24].

Some studies have focused on the primary effects of meteorological droughts on forest ecosystems during drought years or the years following a drought. The monthly precipitation and biophysical parameters of Amazon forest was analyzed using spaceborne hyperspectral metrics from January 2001 to January 2002 [27]. Results illustrated that canopy water content, light-use efficiency, and net primary productivity (NPP) were sensitive to the drought. The impacts of a 2005 drought on the gross primary productivity (GPP), expressed as the enhanced vegetation index (EVI), of Amazonia were analyzed [28]. It was concluded that EVI was associated with radiation income rather than the precipitation amount. GPP in TDFs in Santa Rosa National Park (SRNP), Costa Rica declined by $13 \%$ and $42 \%$ during drought seasons of 2014 and 2015, respectively [13]. Other studies assessed the primary impacts of droughts on the forest ecosystem from a long-term perspective. The influences of drought on NPP across mainland China from 1982 to 2015 was analyzed using Carnegie Ames Stanford Application (CASA) and SPEI [29]. A positive correlation between the annual NPP and SPEI was observed in most areas of mainland China. Besides, the temporal relationship was positive in summer 
and autumn, while a negative relation was detected in the spring and winter. Phillips et al. [30] found that relative to pre-2005 conditions (1980-2004), Amazon forest subjected to a $100 \mathrm{~mm}$ increase in water deficit lost 5.3 megagrams of aboveground biomass of carbon per hectare. Brando et al. [31] concluded that GPP declined with vapor pressure deficit (VPD) and decreased precipitation and plant available water (PAW) in sparse forested areas in the Amazon from 2000 to 2008. In densely forested areas, EVI was associated with leaf flushing rather than leaf area index (LAI) or any climate variables. Williams et al. [15] found that the forest drought stress index (FDSI), which is associated with tree productivity, was approximately equally influenced by warm-season temperature and cold-season precipitation for the forest ecosystem in the southwestern United States from 1896 to 2007.

There were only a few studies on the primary effects of meteorological droughts on TDFs from a long-term perspective. This study employed remote sensing-based indices, i.e., the normalized difference vegetation index (NDVI) and land surface temperature (LST) as proxies for forest productivity [32]. The NDVI measures canopy greenness [33] and the LST reflects the evapotranspiration of plants [34].

Relationships between remote-sensing indices (NDVI and LST) and meteorological drought indices have been explored in different regions. The relationship of monthly NDVI with multiscale SPIs was quantified in the growing season across the north and central U.S. Great Plains from 1989 to 2000 [33]. Results illustrated NDVI-SPI correlations varied significantly by month and the best correlations occurred in the middle of the growing season. The temporal response of the satellite derived NDVI to precipitation in Kansas, U.S. from 1989 to 1997 was tested [35]. It was concluded that the average NDVI values during the growing season had a high correlation with the cumulated precipitation of the current growing season plus the preceding seven months (15-month duration). The relationship between the normalized vegetation supply water index (NVSWI), (calculated using the NDVI and LST) and the precipitation condition index (PCI) was conducted in Yunnan province of China from 2008 to 2011 [36]. It was found that the NVSWI correlated best with 64 days of earlier rainfall in terms of the cropland and shrubland, while evergreen forest was sensitive to precipitation 90 days earlier.

The correlation between the NDVI and LST was also explored around the world [37,38]. This is because the correlation can reflect the limiting factor for vegetation growth, which is a key component for drought monitoring. Specifically, when the NDVI-LST correlation is significantly negative, resulting from the cooling effect of canopy transpiration, water availability is a limiting factor for vegetation growth; when the NDVI-LST correlation is significantly positive, attributable to warming inducing an increase in plant biomass, cover, and NPP, energy or air temperature is a limiting factor [39]. In TDFs, the limiting factor for plant growth is water availability $[13,40]$. However, the importance of precipitation for TDFs growth in different seasons (i.e., dry, wet, and transitional seasons) is not discussed in detail.

In this context, the objective of this study is to explore how TDFs temporally respond to meteorological drought at monthly and seasonal scales from a long-term perspective and how precipitation is important to the growth of TDFs in different seasons (dry, dry-to-wet transitional, wet, and wet-to-dry transitional seasons). Specifically, we try to answer the following questions: (1) How do the NDVI and LST temporally respond to SPIs in TDFs; and (2) what is the relationship between the NDVI and LST in different seasons in TDFs? This study will contribute to a deeper understanding of the primary response of TDFs to meteorological drought triggered by climate change and the importance of water to the growth of TDFs.

\section{Methods}

\subsection{Study Site}

The study was conducted at the Santa Rosa National Park Environmental Monitoring Super Site (SRNP-EMSS; Figure 1) in Guanacaste province of Costa Rica. The SRNR-EMSS is part of the regional 
conservation area known as the Area de Conservacion Guanacaste (ACG) in the northwest of Costa Rica. The SRNP-EMSS ranges from $85^{\circ} 31^{\prime} \mathrm{W}-85^{\circ} 39^{\prime} \mathrm{W}$ and $10^{\circ} 48^{\prime} \mathrm{N}-10^{\circ} 56^{\prime} \mathrm{N}$, covering approximately $109 \mathrm{~km}^{2}$ with a mean slope of 7\%. The SRNP-EMSS had been a part of a cattle ranch hacienda for almost 200 years until 1971. After that, the SRNP-EMSS deFfveloped into a mosaic of diverse vegetation cover dominated by secondary forests in various stages of regeneration [11,34,41]. The SRNP-EMSS receives a mean annual rainfall of $1391 \mathrm{~mm}$ with high variability (915-2558 $\mathrm{mm}$ per year) and has a stable mean annual temperature of $26^{\circ} \mathrm{C}$ [11,34]. The SRNP-EMSS is characterized by a three-month dry season from January to March when there is almost no rainfall and the majority of deciduous vegetation loses its leaves (Figure 2). After the dry season, the rainfall starts to increase in April and sharply rises in May. As such, April and May are considered the dry-to-wet transitional season. The wet season is between June and October when the precipitation stays at a high level. A short dry period can occur in late July or August caused by a short intensification of trade wind activity [42]. November and December are considered a wet-to-dry transitional season when the precipitation declines sharply.

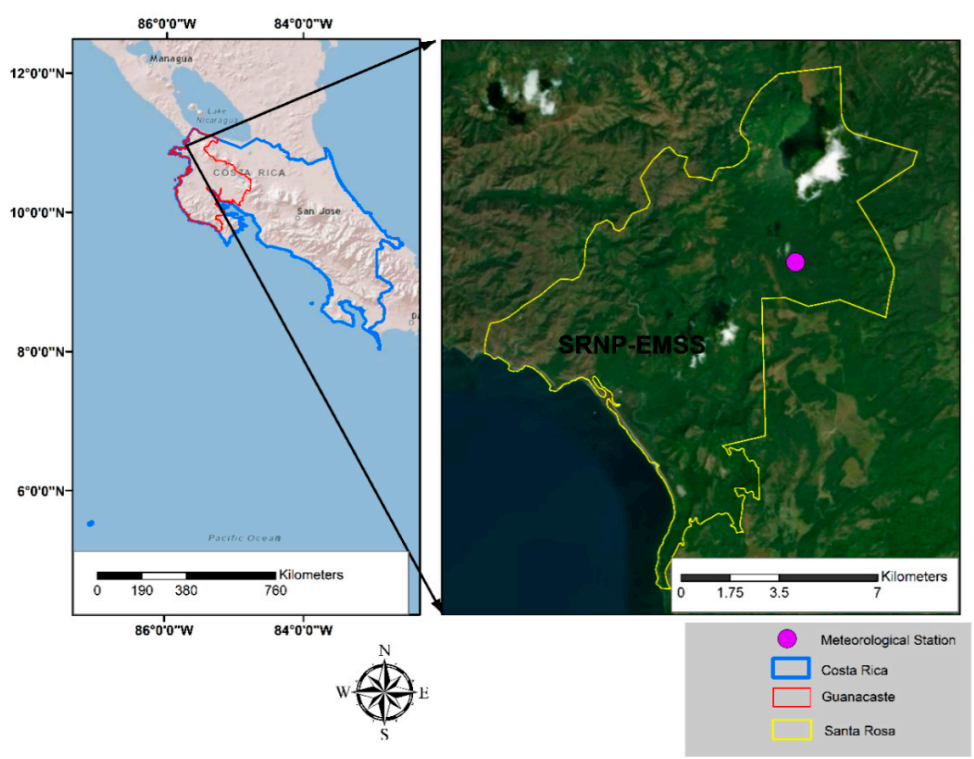

Figure 1. Study area: Santa Rosa National Park Monitoring Super Site (SRNP-EMSS).

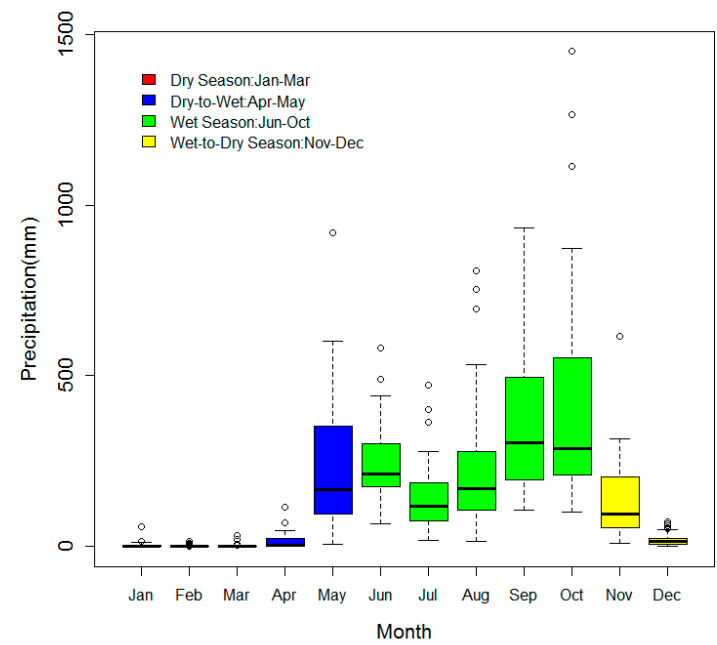

Figure 2. The monthly precipitation distribution at SRNP-EMSS from June 1976 to December 2016. 


\subsection{The NDVI and LST as Response Variables to Drought}

As a widely used vegetation index, the normalized difference vegetation index (NDVI) is calculated based on reflectance at the red and near-infrared wavelengths. It can be used to reflect the vegetation vigor and greenness [43]. The land surface temperature (LST) derived from the thermal band is related to vegetation water stress, soil moisture, and evapotranspiration [43]. The NDVI and LST are widely used in the drought monitoring of terrestrial ecosystem dynamics on remote sensing [33] because temporal variations in the NDVI and LST can reflect the primary response, the reduction in productivity, to meteorological drought. Sixteen-day and eight-day Terra Moderate Resolution Imaging Spectroradiometer (MODIS) products with $250 \mathrm{~m}$ (MOD13Q1, collection v006) and $1000 \mathrm{~m}$ resolutions (MOD11A2, collection v006), respectively, from March 2000 to March 2017 were downloaded from NASA's website (http://reverb.echo.nasa.gov/reverb/). We first resampled the LST images to $250 \mathrm{~m}$ and then converted the NDVI and LST images to a Universal Transverse Mercator projection with central zone $16 \mathrm{~N}^{\circ}$ and WGS84 using the nearest interpolation algorithm. Daily NDVI and LST images are composited over 16 and 8 days by using the maximum NDVI value and the average of clear-sky LSTs for each pixel $[40,44]$, which is used to minimize the effect of cloud contamination. Despite the compositing procedure minimizing the noise in the data, some noise from sources such as changes in atmospheric condition and variations in the sun-target-sensor geometry may remain [45]. It is impossible to correct all error sources using physical-based procedure [45]. In this study, we adopt the pixels with good quality (referred as "Use with confidence") using the per-pixel quality assessment science data sets. Then, monthly NDVI and LST products were aggregated by considering the weight of the number of days belonging to each month after removing the missing data [46].

\subsection{Temporal Correlations Between the NDVI and LST and SPIs}

We used the SPI as the meteorological drought index due to its lower requirement of data and its multiscale character [18]. Daily precipitation was gathered from in the SRNP-EMSS meteorological station from June 1976 to December 2016. The data were tabulated in CSV format. We aggregated the daily data to monthly data [16]. Multiple scales (1 to 12 months) of SPIs were then calculated from the monthly precipitation [16] that is aggregated from daily precipitation.

The responses of the NDVI and LST to meteorological drought were conducted using temporal correlation analysis of the NDVI and LST and multiple SPIs. Time duration and time lag are integrated into the temporal correlation analysis [33]. Time duration refers to the time scales of SPIs [18]. In this case, time lag refers to the interval between the occurrence of precipitation and the change in remote-sensing parameters [33].

In each month, from January to December, the correlations between the monthly NDVI and LST and the corresponding SPIs were calculated, with SPIs in 12 different time durations (1-12 months) and six different time lags ( $0-5$-month lags). As a result, there were 72 correlation coefficients for each month as shown in Table 1. We can assess the temporal patterns (duration and lag) of SPIs that most significantly affected the current NDVI and LST in each month using the maximum SPI-NDVI and the minimum SPI-LST coefficients, respectively, based on the assumption that a meteorological drought can lead to lower NDVI and higher LST.

We also calculated the correlation coefficients between the average NDVI and LST in the dry, dry-to-wet, wet, and wet-to-dry season for various years and the corresponding temporal patterns of the SPIs. In Santa Rosa, the four seasons lasted 3 months, 2 months, 5 months, and 2 months, respectively. Thus, the time duration of the SPIs for the four seasons ranged from 3 months (the current dry season), 2 months (the current dry-to-wet season), 5 months (the current wet season), and 2 months (the current wet-to-dry season) to 2 years ago (24 months ago). The parameters of SPIs that most significantly affected the seasonal average NDVI and LST was obtained via the maximum SPI-NDVI and the minimum SPI-LST coefficients, respectively. 
Table 1. The temporal patterns (12 time durations * 6 time lags) of correlations between the SPIs and the NDVI and LST in each month. The numbers in the cells show the time period of the SPIs. For example, zero shows the current month, one indicates the first previous month, and 0-1 shows the period from the current month to the first current month.

\begin{tabular}{ccccccccccccc}
\hline & \multicolumn{10}{c}{ Duration } \\
\cline { 2 - 28 } & $\mathbf{1}$ & $\mathbf{2}$ & $\mathbf{3}$ & $\mathbf{4}$ & $\mathbf{5}$ & $\mathbf{6}$ & $\mathbf{7}$ & $\mathbf{8}$ & $\mathbf{9}$ & $\mathbf{1 0}$ & $\mathbf{1 1}$ & $\mathbf{1 2}$ \\
\hline 0 & 0 & $0-1$ & $0-2$ & $0-3$ & $0-4$ & $0-5$ & $0-6$ & $0-7$ & $0-8$ & $0-9$ & $0-10$ & $0-11$ \\
1 & 1 & $1-2$ & $1-3$ & $1-4$ & $1-5$ & $1-6$ & $1-7$ & $1-8$ & $1-9$ & $1-10$ & $1-11$ & $1-12$ \\
2 & 2 & $2-3$ & $2-4$ & $2-5$ & $2-6$ & $2-7$ & $2-8$ & $2-9$ & $2-10$ & $2-11$ & $2-12$ & $2-13$ \\
3 & 3 & $3-4$ & $3-5$ & $3-6$ & $3-7$ & $3-8$ & $3-9$ & $3-10$ & $3-11$ & $3-12$ & $3-13$ & $3-14$ \\
4 & 4 & $4-5$ & $4-6$ & $4-7$ & $4-8$ & $4-9$ & $4-10$ & $4-11$ & $4-12$ & $4-13$ & $4-14$ & $4-15$ \\
5 & 5 & $5-6$ & $5-7$ & $5-8$ & $5-9$ & $5-10$ & $5-11$ & $5-12$ & $5-13$ & $5-14$ & $5-15$ & $5-16$ \\
\hline
\end{tabular}

\subsection{The Seasonal Correlation Between the Average NDVI and LST}

The NDVI-LST correlations vary spatially and temporally. To evaluate the predominant factors for the growth of TDFs in four seasons, Pearson correlation analysis was conducted between the average NDVI and the average LST in the dry, dry-to-wet, wet, and wet-to-dry season, respectively.

\section{Results}

\subsection{The Monthly Distribution of the NDVI and LST at SRNP-EMSS}

Figure 3 shows the monthly distribution of NDVI and LST from March 2000 to March 2017. Overall, the median NDVI in the dry and the dry-to-wet seasons was lower than in the wet and wet-to-dry seasons, while the LST shows completely opposite trends. As is shown in Figure 3a, the median value of the NDVI decreased from 0.71 to 0.52 in the dry season from January to March. In the dry-to-wet season, it reached the lowest level at around 0.50 in April and increased to 0.55 in May. In the wet season, the median NDVI dramatically increased to 0.81 in June and stayed at a high level (around 0.85 ) through the wet season. In the wet-to-dry season, the NDVI stayed at a high level (around 0.8) with a slight decline.

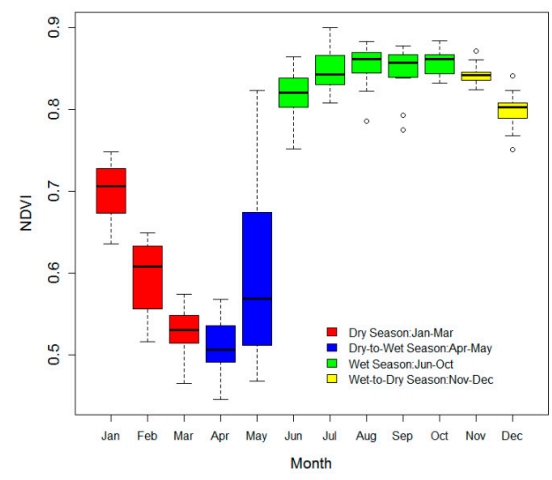

(a) NDVI distribution

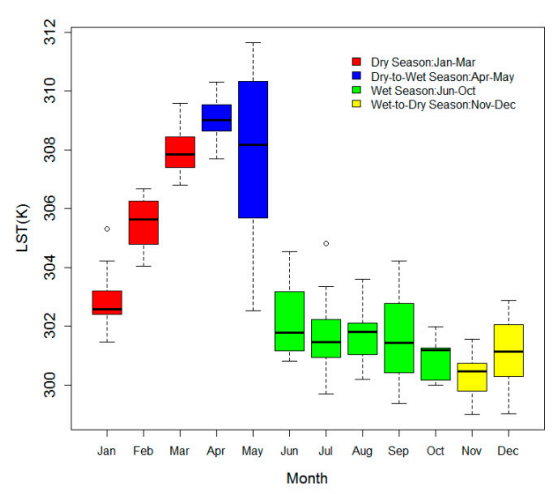

(b) LST distribution

Figure 3. The monthly distribution of the normalized difference vegetation index (NDVI) and land surface temperature (LST) at the SRNP-EMSS from March 2000 to March 2017.

The median LST increased from $302.3 \mathrm{~K}$ to $308 \mathrm{~K}$ in the dry season (Figure $3 \mathrm{~b}$ ). During the dry-to-wet season, it increased to $309 \mathrm{~K}$ in April and decreased to $308.2 \mathrm{~K}$ in May. It sharply declined to around $302 \mathrm{~K}$ in June and kept relatively stable (between $301 \mathrm{~K}$ and $302 \mathrm{~K}$ ) during the wet season. In the wet-to-dry season, the median LST slightly declined to $301 \mathrm{~K}$ in November and increased to 
$302 \mathrm{~K}$ in December. The NDVI and LST variations in the dry season were much higher than in the wet season. Both the NDVI and LST experienced the largest variations in May.

\subsection{The Temporal Response of the NDVI and LST to Meteorological Drought}

Table 2 shows the maximum SPI-NDVI correlation and the minimum SPI-LST correlation among 72 temporal relationships (time durations (1-12 months) and time lags (0-5-month lags)) in each month. The NDVI and LST can be well explained by the SPIs for most months. Low maximum SPI-NDVI correlations were seen in August, October, November, and December, and high minimum SPI-LST correlations were seen in November. The maximum SPI-NDVI and the minimum SPI-LST correlation varied with the combination of the time duration, time lag and month. The maximum SPI-NDVI and the minimum SPI-LST correlations were obtained at the same combination of the time durations and time lags in January, February, and March (the dry season). They also had the same time lags in April and May (the dry-to-wet season). The combinations for each month during June and December (the wet season and wet-to-dry season) were different, except for September. The time lags for the significant minimum SPI-LST correlations were no longer than the corresponding maximum SPI-NDVI during June and December.

Table 2. The maximum temporal correlation coefficients ( $r$-value) between the NDVI and the corresponding SPIs with 12 different time durations (1-12 months) and 6 different time lags (0-5 months), and the minimum temporal correlation coefficients ( $r$-value) between the LST and the corresponding SPIs in each month. The stars indicate that the $p$-values are less than 0.05 . No stars indicate $p$-values greater than 0.05 .

\begin{tabular}{ccccc}
\hline Period & \multicolumn{2}{c}{ The Maximum SPI-NDVI Correlation } & \multicolumn{2}{c}{ The Minimum SPI-LST Correlation } \\
\hline Month & Time & r-Value & Time & r-Value \\
\hline January & Duration $=5 \mathrm{Lag}=0$ & $0.55^{*}$ & Duration $=5 \mathrm{Lag}=0$ & $-0.68^{*}$ \\
February & Duration $=10 \mathrm{Lag}=0$ & $0.79^{*}$ & Duration $=10 \mathrm{Lag}=0$ & $-0.70^{*}$ \\
March & Duration $=12 \mathrm{Lag}=0$ & $0.87^{*}$ & Duration $=12 \mathrm{Lag}=0$ & $-0.64^{*}$ \\
April & Duration $=12 \mathrm{Lag}=0$ & $0.63^{*}$ & Duration $=10 \mathrm{Lag}=0$ & $-0.62^{*}$ \\
May & Duration $=2 \mathrm{Lag}=1$ & $0.76^{*}$ & Duration $=3 \mathrm{Lag}=1$ & $-0.55^{*}$ \\
June & Duration $=11 \mathrm{Lag}=2$ & $0.65^{*}$ & Duration $=12 \mathrm{Lag}=1$ & $-0.76^{*}$ \\
July & Duration $=2 \mathrm{Lag}=4$ & $0.66^{*}$ & Duration $=6 \mathrm{Lag}=2$ & $-0.77^{*}$ \\
August & Duration $=3 \mathrm{Lag}=0$ & 0.41 & Duration $=9 \mathrm{Lag}=0$ & $-0.70^{*}$ \\
September & Duration $=1 \mathrm{Lag}=4$ & $0.81^{*}$ & Duration $=1 \mathrm{Lag}=4$ & $-0.69^{*}$ \\
October & Duration $=8 \mathrm{Lag}=5$ & 0.34 & Duration $=1 \mathrm{Lag}=0$ & $-0.54^{*}$ \\
November & Duration $=1 \mathrm{Lag}=2$ & -0.04 & Duration $=5 \mathrm{Lag}=5$ & -0.42 \\
December & Duration $=3 \mathrm{Lag}=0$ & 0.38 & Duration $=7 \mathrm{Lag}=0$ & $-0.79 *$ \\
\hline
\end{tabular}

Table 3 shows the maximum SPI-NDVI correlation and the minimum SPI-LST correlation in each season. The seasonal temporal correlations varied with the time duration, time lag and season. The maximum SPI-NDVI correlations are significant $(p<0.05)$ except in the wet-to-dry season, and the minimum SPI-LST correlations are significant $(p<0.05)$ for all the seasons. In addition, the absolute values of the minimum SPI-LST correlations in the dry, wet, and wet-to-dry seasons $(0.83,0.69$, and 0.82 , respectively) are higher than the maximum SPI-NDVI correlations ( $0.78,0.78$ and 0.27 , respectively). In the dry-to-wet season, the maximum SPI-NDVI correlation (0.78) was higher than the absolute minimum SPI-LST correlation (0.55). In addition, the time durations for the maximum SPI-NDVI correlations $(9,2,6$, and 3 months) were shorter than the corresponding absolute minimum SPI-LST correlations $(11,3,13$, and 3 months) in each season. The time lag for the maximum SPI-NDVI correlation in the wet season (four months) was longer than the minimum SPI-LST correlation (one month). They had the same time lags in the dry, dry-to-wet, and wet-to-dry season ( 0,1 , and 0 months, respectively).

Figure 4 shows the SPIs-NDVI and SPIs-LST correlations as a function of time duration, with 1-month increments given the fixed time lags in each season. The time lags were selected 
based on the maximum SPI-NDVI and the minimum SPI-LST correlations in each season (Table 3). In the dry season, with the same 0-month time lag, the SPIs-NDVI correlations reached a very high level ( $r$-values $>0.75)$ at durations between 8 and 17 months(Figure 4a), and the SPIs-LST correlations were at a very low level (r-values $<-0.8)$ at durations between 11 and 16 months (Figure $4 a)$. In the dry-to-wet season, given the same one-month time lag, the SPIs-NDVI correlation reached a very high level ( $r$-values $>0.75$ ) at two- and three-month durations (Figure $4 \mathrm{~b}$ ), and the SPIs-LST correlation reached a moderately low level ( $r$-values $<-0.5)$ at the two-month duration(Figure $4 \mathrm{~b})$. In the wet season, the SPIs-NDVI correlation reached a high level ( $r$-values $>0.65)$ at durations between five months and seven months given a time lag of four months (Figure 4c),. The SPIs-LST correlations reached a low level at durations between 5 months and 10 months given a time lag of 1 month (Figure 4c). In the wet-to-dry season, the SPIs-LST correlations reached ( $r$-values $<-0.8$ ) a very low level at durations between 8 and 13 months (Figure $4 \mathrm{~d}$ ). The SPIs-LST correlations were not significant for the entire duration (Figure 4d).

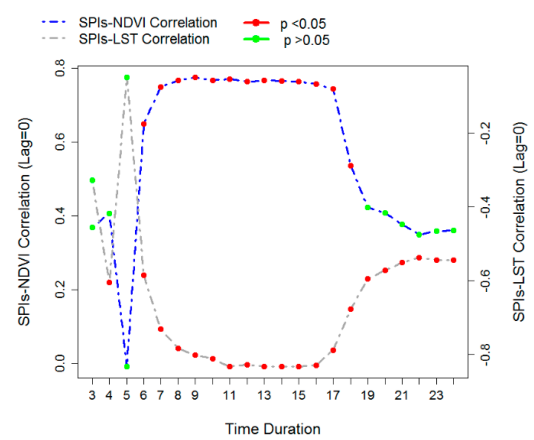

(a) Dry season

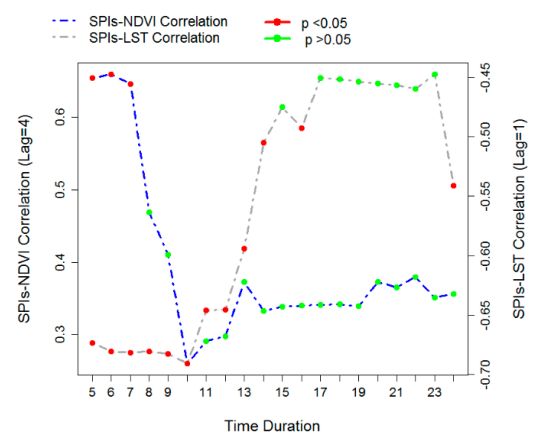

(c) Wet season

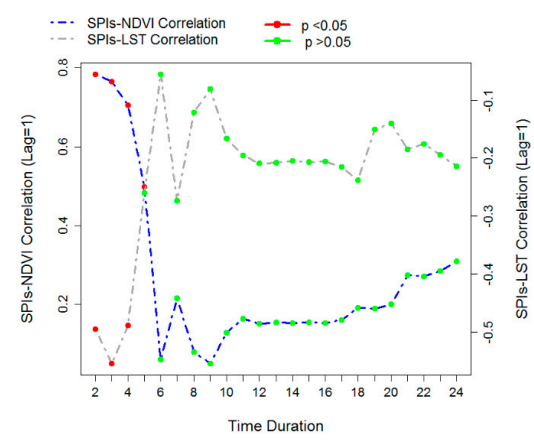

(b) Dry-to-wet season

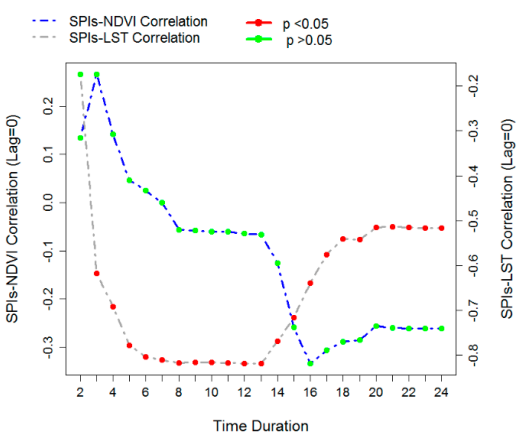

(d) Wet-to-dry season

Figure 4. Correlation coefficients as a function of time duration in the fixed time lag corresponding to the maximum SPI-NDVI correlation and the minimum SPI-LST correlation in the dry, dry-to-wet, wet and wet-to-dry season. Red dots and green dots indicate the SPI-NDVI and SPI-LST correlations with p-values less than 0.05 and no less than 0.05 , respectively.

Table 3. The maximum temporal correlation coefficients ( $r$-value) between the average NDVI and the corresponding SPIs with different time durations (the current season-24 months) and 6 different time lags ( $0-5$ months), and the minimum temporal correlation coefficients ( $r$-value) between the average LST and the corresponding SPIs with different time durations (the current season-24 months) and 6 different time lags ( $0-5$ months) in each season. The stars indicate $\mathrm{p}$-values less than 0.05 . No stars indicate that $p$-values are greater than 0.05 .

\begin{tabular}{ccccc}
\hline Period & \multicolumn{2}{c}{$\begin{array}{c}\text { The Maximum } \\
\text { SPI-NDVI Correlation }\end{array}$} & \multicolumn{2}{c}{$\begin{array}{c}\text { The Minimum } \\
\text { SPI-LST Correlation }\end{array}$} \\
\hline Season & Time & $r$-value & Time & $r$-value \\
\hline Dry season & Duration $=9$ Lag $=0$ & $0.78^{*}$ & Duration $=11$ Lag $=0$ & $-0.83 *$ \\
\hline
\end{tabular}


Table 3. Cont.

\begin{tabular}{ccccc}
\hline Period & \multicolumn{2}{c}{$\begin{array}{c}\text { The Maximum } \\
\text { SPI-NDVI Correlation }\end{array}$} & \multicolumn{2}{c}{$\begin{array}{c}\text { The Minimum } \\
\text { SPI-LST Correlation }\end{array}$} \\
\hline Season & Time & $r$-value & Time & $r$-value \\
\hline Dry-to-wet season & Duration $=2 \mathrm{Lag}=1$ & $0.78^{*}$ & Duration $=3 \mathrm{Lag}=1$ & $-0.55^{*}$ \\
Wet season & Duration $=6 \mathrm{Lag}=4$ & $0.66^{*}$ & Duration $=10 \mathrm{Lag}=1$ & $-0.69 *$ \\
Wet-to-dry season & Duration $=3 \mathrm{Lag}=0$ & 0.27 & Duration $=13 \mathrm{Lag}=0$ & $-0.82 *$ \\
\hline
\end{tabular}

\subsection{Correlation Between the Seasonal Average NDVI and LST}

Figure 5 shows the correlations between the average NDVI and the average LST in each season. In the dry and dry-to-wet season, they were strongly negatively correlated ( $r$-value $=-0.85$ and -0.88 , $p<0.001$ and 0.001$)$. In the wet season, they had a medium negative correlation ( $r$-value $=-0.52$, $p=0.029)$. In the wet-to-dry season, the correlation was not significant $(r$-value $=-0.11, p=0.672)$.

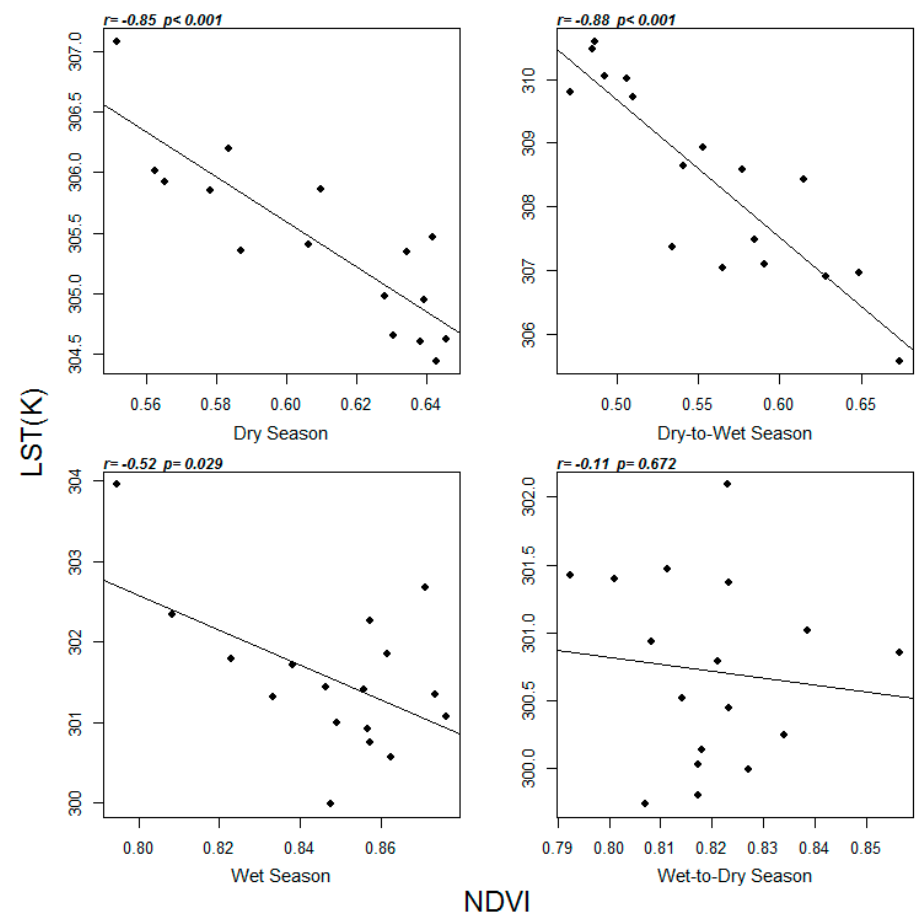

Figure 5. The seasonal correlations between the average NDVI and the LST in the dry, dry-to-wet, wet, and wet-to-dry season from March 2000 to March 2017 ( $\mathrm{N}=17$ year).

\section{Discussion}

\subsection{Phenologically Dependent Responses of NDVI and LST to Meteorological Drought}

The patterns of the NDVI and LST in response to meteorological drought strongly depend on the seasonality in the TDFs. Previous studies have shown the temporal relationship between biophysical parameters and climatic factors in various terrestrial ecosystems across the words [47]. In this study, NDVI was strongly sensitive to precipitation in the dry and dry-to-wet season, and was highly sensitive in the wet season, and was not sensitive in the wet-to-dry season. LST was strongly affected by variations in rainfall in the dry and wet-to-dry season, highly affected in the wet season, and moderately impacted in the dry-to-wet season. Results indicated NDVI and LST reflecting different biophysical processes $[33,34]$. The NDVI describes the vegetation greenness and deciduousness of TDFs and LST describes the temperature and evapotranspiration on the surface. The sensitivity of the deciduousness and canopy evapotranspiration in the dry season can be interpreted that plants 
under water deficit stress exhibit decline in both photosynthesis and transpiration rates [48]. The leaf flush in the dry-to-wet season was driven by the precipitation [13]; and these new leaves, in turn, cooled down the canopy temperature due to increased canopy evapotranspiration [49]. Greenness and canopy temperature in the wet season were relatively resistant to the meteorological drought. It can be interpreted that the leaves were relatively saturated and abundant water content was stored in the root regions, which can reduce the influence of drought on canopy evapotranspiration [50]. The maximum SPI-NDVI correlation was weak in August and high in September (Table 3), which resulted from short-term rainfall shortage at the end of July. The results indicated that canopy evapotranspiration was more sensitive than a short-term rainfall deficiency, and greenness was more sensitive to precipitation after a dry period. The canopy greenness in the wet-to-dry season was less impacted by precipitation. This is because abundant water content in the roots can mitigate the leaf fall at the beginning of dry period. Canopy evapotranspiration was strongly influenced by rainfall, confirming it was sensitive to a short-term rainfall deficiency as in August.

\subsection{Water Availability, Duration, and Timing as Key Factors Controlling the NDVI and LST}

The temporal responses of the NDVI and LST to water deficiency (magnitude of meteorological drought) largely depend on its duration (the period for rainfall accumulation) and the timing (the onset for rainfall) of precipitation [51].

In the dry season, the strongest correlations between the average NDVI and LST and SPIs were found when the precipitation was integrated over 9 and 11 months, which included the entire current dry season ( 3 months) plus the 6 and 8 preceding months, respectively. The average NDVI was affected by the precipitation of not only the current dry season, but also the precipitation of the wet and wet-to-dry season of the preceding year, and the average LST was influenced by the precipitation of the current dry season, as well as the previous dry-to-wet, wet, and wet-to-dry seasons. This indicates that the greenness and canopy evapotranspiration in the dry season were strongly influenced by a relatively long period of precipitation. This might be interpreted that, much of the precipitation is stored in the root zone when the rainfall is abundant in the previous year, which can mitigate leaf fall and provide water for evapotranspiration in TDFs in the dry season.

In the dry-to-wet season, the SPI-NDVI correlation peaked at the duration of two months and the lag of one month, indicating the average NDVI was strongly affected by the accumulated precipitation in March and April of the current year. The SPI-LST reached the bottom at the duration of three months and the lag of one month, showing that the average LST was moderately influenced by the total rainfall received during February to April of the current year. It revealed that the leaf flush in the dry-to-wet season, especially in May, was strongly controlled by the sporadic rainfall during March to April instead of in May when the precipitation was abundant. Moreover, the canopy evapotranspiration was influenced by the accumulated precipitation during February to April of the current year when the rainfall was less. The result illustrated that canopy evapotranspiration and especially leaf flush were sensitive to the timing of precipitation. Previous studies have shown the lag effect of climate factors on biophysical parameters differ in diverse terrestrial ecosystems [47].

In the wet season, the average NDVI was highly affected by the accumulated precipitation during January to June of the current year, and the average LST was highly influenced by the total rainfall during the previous August to the current September. This indicated that greenness was affected by both the magnitude and timing of precipitation. The canopy evapotranspiration was more affected by the magnitude of precipitation rather than the timing of precipitation.

The average NDVI in the wet-to-dry season did not significantly correlate with SPIs; the average LST was strongly influenced by the accumulated precipitation during the previous November to the current December, indicating that the evapotranspiration in TDFs is only sensitive to the magnitude of precipitation for a long period. These results are consistent with previous finding that LST are more sensitive to onset of drought events [43,44]. 


\subsection{Estimate the Primary Response of TDFs to Meteorological Drought}

The primary response of TDFs to water deficiency is a decline in primary productivity $[24,52]$. Previous studies have shown the solar-induced chlorophyll fluorescence (SIF), a direct proxy of actual vegetation photosynthesis, was used to monitor the drought effects on vegetation productivity [49]. Besides, the MODIS gross primary productivity (GPP) algorithm [53] estimates the GPP as a function of the photosynthetically active radiation (PAR), NDVI, LST, air temperature, and maximum light use efficiency $\left(\varepsilon_{\max }\right)$. Among them, the NDVI, LST, and $\varepsilon_{\max }$ are relative to vegetation characteristics. The MODIS GPP algorithm estimates the $\varepsilon_{\max }$ based on the biome properties look-up table (BPLUT), which mistakes TDFs for the type of desert. However, the primary response of TDFs to meteorological drought can be indirectly estimated based on the temporal correlation analysis of NDVI and LST and SPIs (Figures 4 and 5), based on the hypothesis that $\varepsilon_{\max }$ varies with season but not with year. The GPP of TDFs is affected by meteorological drought when both NDVI and LST have significant correlations with specific SPIs simultaneously.

In the dry season, the SPI-NDVI correlations reached a high level from a duration of 8 months to a duration of 17 months for the fixed lag of 0 months, and the SPI-LST correlations reached a low level from a duration of 11 months to a duration of 16 months for the fixed lag of 0 months (Figure 4). The GPP was considered to respond to the precipitation with a duration of 11 months (the minimum intersection) and a lag of 0 months. The NDVI-LST correlation was highly negative (Figure 5), indicating that water availability is the predominant factor for the growth of TDFs in the dry season [43]. We inferred that the average GPP is strongly influenced by the accumulated precipitation from the preceding February to the current March. In the dry-to-wet season, the SPI-NDVI correlations reached a high level from a duration of two to three months for the fixed lag of one month, and the SPI-LST correlations reached a low level at a duration of three months for the fixed lag of one month (Figure 4). Thus, GPP responds to the precipitation with a duration of three months and a lag of one month. In addition, the NDVI-LST correlation was highly negative in the dry-to-wet season (Figure 5). As such, we inferred that the average GPP was strongly affected by the total precipitation from February to April of the current year. In the wet season, the average NDVI was highly affected by the total precipitation from January to June of the current year. The average LST was highly influenced by the accumulated precipitation from the previous December to the current September. The NDVI-LST correlation was moderately negative. We inferred that the GPP is moderately influenced by the precipitation from January to June of the current year based on the hypothesis that the greenness is a more important parameter than evapotranspiration for calculating the GPP [53]. In the wet-to-dry season, The NDVI-LST correlation was not significant (Figure 5), indicating that water availability is not the dominant factor in the growth of TDFs because of abundant water content in the root region [50]. As such, we can infer that GPP is not influenced by precipitation in the wet-to-dry season. These inferences are consistent with the results in Figure S1 (Supplementary Materials).

\section{Conclusions}

The response of the NDVI and the LST to the SPIs is crucial to understand how TDFs respond to meteorological droughts. In this study, we conducted temporal correlations between the MODIS-derived NDVI and LST to the SPIs between March 2000 and March 2017 in the TDFs at the Santa Rosa National Park Monitoring Super Site (SRNP-EMSS) at monthly and seasonal scales.

We found that the NDVI and LST largely depend on the seasonality, as well as the magnitude, duration, and timing of precipitation. In the dry season, the average NDVI and LST were sensitive to the magnitude of a long period of precipitation. In the dry-to-wet season, the average NDVI and LST were strongly and moderately sensitive to the magnitude of short-term precipitation and the timing of precipitation, respectively. In the wet season, the average NDVI was highly sensitive to half-year accumulated precipitation. The average LST was highly sensitive to the magnitude of long-term precipitation. In the wet-to-dry season, precipitation is not a key factor controlling NDVI, but average LST is highly sensitive to the magnitude of long-term precipitation. 
Regarding the GPP response of the SRNP-EMSS to meteorological drought, we conclude that GPP is affected by yearly, short-term, and half-year accumulated precipitation in the dry, dry-to-wet season, and wet season, respectively. In the wet-to-dry season, GPP was not influenced by precipitation amount.

There are several limitations that should be considered in the future. First, the GPP response to meteorological drought was estimated indirectly. To validate our results and reduce the uncertainties, accurate estimate of GPP is necessary. Multiple data resources (remote sensing, in-situ, and modelling) should be integrated to estimate GPP in the future. Secondly, the atmospheric CO2 concentrations increased during the past century, which cause a warming climate and then enhance photosynthesis efficiency of vegetation and vegetation productivity [54]. Nitrogen deposition is also a factor affecting vegetation productivity [54]. In the future, assessing the response of TDFs productivity to climate factors should also consider the effects of $\mathrm{CO} 2$ concentrations and Nitrogen deposition on TDFs productivity.

Supplementary Materials: The following are available online at http://www.mdpi.com/2072-4292/12/14/2341/s1, Figure S1: The seasonal average NDVIs and LSTs and the selected SPIs from 2000 to 2016.

Author Contributions: A.S.-A. proposed an idea about the impact of drought on tropical dry forests. L.Z. designed the experiments and carried them out. S.C. provided IDL algorithm support. A.Z. provided a new method about temporal correlation analysis. L.Z. prepared the manuscript with contributions from all co-authors. All authors have read and agreed to the published version of the manuscript.

Funding: This research was funded by Special Foundation for National Science and Technology Basic Research Program of China(2019FY202503), State Key Laboratory of Resources and Environmental Information System, Program of Education Department of Hebei Province, China (NO. BJ2018043).

Conflicts of Interest: The authors declare no conflicts of interest.

\section{References}

1. Sanchez-Azofeifa, G.A.; Quesada, M.; Rodríguez, J.P.; Nassar, J.M.; Stoner, K.E.; Castillo, A.; Cuevas-Reyes, P. Research priorities for Neotropical dry forests. Biotropica 2005, 37, 477-485.

2. Murphy, P.G.; Lugo, A.E. Ecology of tropical dry forest. Annu. Rev. Ecol. Syst. 1986, 17, 67-88. [CrossRef]

3. Quesada, M.; Sanchez-Azofeifa, G.A.; Alvarez-Anorve, M.; Stoner, K.E.; Avila-Cabadilla, L.; Calvo-Alvarado, J.; Fernandes, G.W. Succession and management of tropical dry forests in the Americas: Review and new perspectives. For. Ecol. Manag. 2009, 258, 1014-1024. [CrossRef]

4. Maass, J.M.; Balvanera, P.; Castillo, A.; Daily, G.C.; Mooney, H.A.; Ehrlich, P.; García-Oliva, F. Ecosystem services of tropical dry forests: Insights from long-term ecological and social research on the Pacific Coast of Mexico. Ecol. Soc. 2005, 10, 1-23. [CrossRef]

5. Balvanera, P.; Castillo, A.; Martínez-Harms, M.J. Ecosystem services in seasonally dry tropical forests. In Seasonally Dry Tropical Forests; Dirzo, R., Young, H.S., Mooney, H.A., Ceballos, G., Eds.; Island Press: Washington, DC, USA, 2011; pp. 259-277.

6. Calvo-Rodriguez, S.; Sanchez-Azofeifa, A.G.; Duran, S.M.; Espirito-Santo, M.M. Assessing ecosystem services in Neotropical dry forests: A systematic review. Environ. Conserv. 2017, 44, 34-43. [CrossRef]

7. Janzen, D.H. Management of habitat fragments in a tropical dry forest: Growth. Ann. Mo. Bot. Gard. 1988, 75, 105-116. [CrossRef]

8. Calvo-Alvarado, J.; McLennan, B.; Sánchez-Azofeifa, A.; Garvin, T. Deforestation and forest restoration in Guanacaste, Costa Rica: Putting conservation policies in context. For. Ecol. Manag. 2009, 285, 931-940. [CrossRef]

9. Portillo-Quintero, C.A.; Sanchez-Azofeifa, G.A. Extent and conservation of tropical dry forests in the Americas. Biol. Conserv. 2010, 143, 144-155. [CrossRef]

10. Hoekstra, J.M.; Boucher, T.M.; Ricketts, T.H.; Roberts, C. Confronting a biome crisis: Global disparities of habitat loss and protection. Ecol. Lett. 2005, 8, 23-29. [CrossRef]

11. Kalacska, M.; Sanchez-Azofeifa, G.A.; Calvo-Alvarado, J.C.; Quesada, M.; Rivard, B.; Janzen, D.H. Species composition, similarity, and diversity in three successional stages of a seasonally dry tropical forest. For. Ecol. Manag. 2004, 200, 227-247. [CrossRef] 
12. Chadwick, W.W.; Paduan, J.B.; Clague, D.A.; Dreyer, B.M.; Merle, S.G.; Bobbitt, A.M.; Nooner, S.L. Voluminous eruption from a zoned magma body after an increase in supply rate at Axial Seamount. Geophys. Res. Lett. 2016, 43, 12063-12070. [CrossRef]

13. Castro, S.M.; Sanchez-Azofeifa, G.A.; Sato, H. Effect of drought on productivity in a Costa Rican tropical dry forest. Environ. Res. Lett. 2018, 13, 045001. [CrossRef]

14. Olukayode Oladipo, E. A comparative performance analysis of three meteorological drought indices. Int. J. Climatol. 1985, 5, 655-664. [CrossRef]

15. Williams, A.P.; Allen, C.D.; Macalady, A.K.; Griffin, D.; Woodhouse, C.A.; Meko, D.M.; Grissino-Mayer, H.D. Temperature as a potent driver of regional forest drought stress and tree mortality. Nat. Clim. Chang. 2013, 3, 292-297. [CrossRef]

16. Patel, N.R.; Chopra, P.; Dadhwal, V.K. Analyzing spatial patterns of meteorological drought using standardized precipitation index. Meterol. Appl. 2007, 14, 329-336. [CrossRef]

17. Onyutha, C. On Rigorous Drought Assessment using Daily Time Scale: Non-Stationary Frequency Analyses, Revisited Concepts, and a New Method to Yield Non-Parametric Indices. Hydrology 2017, 4, 48. [CrossRef]

18. McKee, T.B.; Doeskin, N.J.; Kleist, J. The relationship of drought frequency and duration to time scales. In Proceedings of the Eighth Conference on Applied Climatology, Anaheim, CA, USA, 17-22 January 1993.

19. Vicente-Serrano, S.; Beguería, S.; López-Moreno, J.I. A multiscalar drought index sensitive to global warming: The standardized precipitation evapotranspiration index. J. Clim. 2010, 23, 1696-1718. [CrossRef]

20. Palmer, W.C. Meteorological Drought; Department of Commerce Weather Bureau: Washington DC, USA, 1965; p. 58.

21. Zargar, A.; Sadiq, R.; Naser, B.; Khan, F.I. A review of drought indices. Environ. Rev. 2011, 19, 333-349. [CrossRef]

22. Allen, C.D.; Breshears, D.D.; McDowell, N.G. On underestimation of global vulnerability to tree mortality and forest die-off from hotter drought in the Anthropocene. Ecosphere 2015, 6, 129. [CrossRef]

23. Choat, B.; Jansen, S.; Brodribb, T.J.; Cochard, H.; Delzon, S.; Bhaskar, R.; Hacke, U.G. Global convergence in the vulnerability of forests to drought. Nature 2012, 491, 752-755. Available online: https://www.nature.com/ articles/nature11688 (accessed on 29 November 2012). [CrossRef]

24. Dale, V.H.; Joyce, L.A.; McNulty, S.; Neilson, R.P.; Ayres, M.P.; Flannigan, M.D.; Peterson, C.J. Climate change and forest disturbances: Climate change can affect forests by altering the frequency, intensity, duration, and timing of fire, drought, introduced species, insect and pathogen outbreaks, hurricanes, windstorms, ice storms, or landslides. Bioscience 2001, 51, 723-734. Available online: https://academic.oup.com/bioscience/ article/51/9/723/288247 (accessed on 1 September 2001). [CrossRef]

25. McDowell, N.; Pockman, W.T.; Allen, C.D.; Breshears, D.D.; Cobb, N.; Kolb, T.; Yepez, E.A. Mechanisms of plant survival and mortality during drought: Why do some plants survive while others succumb to drought? New Phytol. 2008, 178, 719-739. [CrossRef]

26. Rouault, G.; Candau, J.; Lieutier, F.; Nageleisen, L.; Martin, J.; Warzée, N. Effects of drought and heat on forest insect populations in relation to the 2003 drought in Western Europe. Ann. For. Sci. 2006, 63, 613-624. [CrossRef]

27. Asner, G.P.; Nepstad, D.; Cardinot, G.; Ray, D. Drought stress and carbon uptake in an Amazon forest measured with spaceborne imaging spectroscopy. Proc. Natl. Acad. Sci. USA 2004, 101, 6039-6044. [CrossRef] [PubMed]

28. Anderson, L.O.; Malhi, Y.; Aragão, L.E.; Ladle, R.; Arai, E.; Barbier, N.; Phillips, O. Remote sensing detection of droughts in Amazonian forest canopies. New Phytol. 2010, 187, 733-750. [CrossRef] [PubMed]

29. Lai, C.; Li, J.; Wang, Z.; Wu, X.; Zeng, X.; Chen, X.; Lian, Y.; Yu, H.; Wang, P.; Bai, X. Drought-Induced Reduction in Net Primary Productivity Across Mainland China from 1982 to 2015. Remote Sens. 2018, 10, 1433. [CrossRef]

30. Phillips, O.L.; Arago, L.E.; Lewis, S.L.; Fisher, J.B.; Lloyd, J.; Lopez-Gonzalez, G.; Quesada, C.A. Drought sensitivity of the Amazon Rainforest. Science 2009, 323, 1344-1347. [CrossRef]

31. Brando, P.M.; Goetz, S.J.; Baccini, A.; Nepstad, D.C.; Beck, P.S.; Christman, M.C. Seasonal and interannual variability of climate and vegetation indices across the Amazon. Proc. Natl. Acad. Sci. USA 2010, 107, 14685-14690. [CrossRef]

32. Liu, J.; Sun, O.J.; Jin, H.; Zhou, Z.; Han, X. Application of two remote sensing GPP algorithms at a semiarid grassland site of north China. J. Plant Ecol. 2011, 4, 302-312. [CrossRef] 
33. Ji, L.; Peters, A.J. Assessing vegetation response to drought in the northern Great Plains using vegetation and drought indices. Remote Sens. Environ. 2003, 87, 85-98. [CrossRef]

34. Cao, S.; Sanchez-Azofeifa, A. Modeling seasonal surface temperature variations in secondary tropical dry forests. Int. J. Appl. Earth Obs. Geoinf. 2017, 62, 122-134. [CrossRef]

35. Wang, J.; Rich, P.M.; Price, K.P. Temporal responses of NDVI to precipitation and temperature in the central Great Plains, USA. Int. J. Remote Sens. 2003, 24, 2345-2364. [CrossRef]

36. Nichol, J.E.; Abbas, S. Integration of remote sensing datasets for local scale assessment and prediction of drought. Sci. Total Environ. 2015, 505, 503-507. [CrossRef] [PubMed]

37. Prihodko, L.; Goward, S.N. Estimation of air temperature from remotely sensed surface observations. Remote Sens. Environ. 1997, 60, 335-346. [CrossRef]

38. Goward, S.N.; Xue, Y.; Czajkowski, K.P. Evaluating land surface moisture conditions from the remotely sensed temperature/vegetation index measurements: An exploration with the simplified simple biosphere model. Remote Sens. Environ. 2002, 79, 225-242. [CrossRef]

39. Karnieli, A.; Bayasgalan, M.; Bayarjargal, Y.; Agam, N.; Khudulmur, S.; Tucker, C.J. Comments on the use of the vegetation health index over Mongolia. Int. J. Remote Sens. 2006, 27, 2017-2024. [CrossRef]

40. Cao, S.; Sanchez-Azofeifa, G.A.; Duran, S.M.; Calvo-Rodriguez, S. Estimation of aboveground net primary productivity in secondary tropical dry forests using the Carnegie-Ames-Stanford approach (CASA) model. Environ. Res. Lett. 2016, 11, 075004. [CrossRef]

41. Janzen, D.H. Costa Rica's area de Conservacin Guanacaste: A long march to survival through non-damaging biodevelopment. Biodiversity 2000, 1, 7-20. [CrossRef]

42. Campos, F.A. A synthesis of long-term environmental change in Santa Rosa, Costa Rica. In Primate Life Histories, Sex Roles, and Adaptability; Kalbitzer, U., Jack, K.M., Eds.; Springer: Cham, Switzerland, 2018; pp. 331-358.

43. Karnieli, A.; Agam, N.; Pinker, R.T.; Anderson, M.; Imhoff, M.L.; Gutman, G.G.; Goldberg, A. Use of NDVI and land surface temperature for drought assessment: Merits and limitations. J. Clim. 2010, 23, 618-633. [CrossRef]

44. Kogan, F.N. Application of vegetation index and brightness temperature for drought detection. Adv. Space Res. 1995, 15, 91-100. [CrossRef]

45. Quiring, S.M.; Ganesh, S. Evaluating the utility of the vegetation condition index (VCI) for monitoring meteorological drought in Texas. Agric. For. Meteorol. 2010, 150, 330-339. [CrossRef]

46. Rhee, J.; Im, J.; Carbone, G.J. Monitoring agricultural drought for arid and humid regions using multi-sensor remote sensing data. Remote Sens. Environ. 2010, 114, 2875-2887. [CrossRef]

47. Wu, D.; Zhao, X.; Liang, S.; Zhou, T.; Huang, K.; Tang, B.; Zhao, W. Time-lag Effects of Global Vegetation Responses to Climate Change. Glob. Chang. Biol. 2015, 21, 3520-3531. [CrossRef] [PubMed]

48. Zhao, J.; Xu, T.; Xiao, J.; Liu, S.; Mao, K.; Song, L.; Yao, Y.; He, X.; Feng, H. Responses of Water use Efficiency to Drought in Southwest China. Remote Sens. 2020, 12, 199. [CrossRef]

49. Zhang, L.; Qiao, N.; Huang, C.; Wang, S. Monitoring Drought Effects on Vegetation Productivity using Satellite Solar-Induced Chlorophyll Fluorescence. Remote Sens. 2019, 11, 378. [CrossRef]

50. Zou, L.; Cao, S.; Sanchez-Azofeifa, A. Evaluating the Utility of various Drought Indices to Monitor Meteorological Drought in Tropical Dry Forests. Int. J. Biometeorol. 2020, 64, 701-711. [CrossRef] [PubMed]

51. Feng, X.; Porporato, A.; Rodriguez-Iturbe, I. Changes in rainfall seasonality in the tropics. Nat. Clim. Chang. 2013, 3, 811-815. [CrossRef]

52. Xiao, X.; Zhang, Q.; Braswell, B.; Urbanski, S.; Boles, S.; Wofsy, S.; Ojima, D. Modeling gross primary production of temperate deciduous broadleaf forest using satellite images and climate data. Remote Sens. Environ. 2004, 91, 256-270. [CrossRef]

53. Running, S.W.; Nemani, R.R.; Heinsch, F.A.; Zhao, M.; Reeves, M.; Hashimoto, H. A continuous satellite-derived measure of global terrestrial primary production. Bioscience 2004, 54, 547-560. [CrossRef]

54. Zhu, Z.; Piao, S.; Myneni, R.; Huang, M.; Zeng, Z. Greening of the Earth and its Drivers. Nat. Clim. Chang. 2016, 6, 791-795. [CrossRef]

(C) 2020 by the authors. Licensee MDPI, Basel, Switzerland. This article is an open access article distributed under the terms and conditions of the Creative Commons Attribution (CC BY) license (http://creativecommons.org/licenses/by/4.0/). 